\title{
Capacity Assessment for Integrated Coastal Management in India
}

\author{
Devaraj Asir Ramesh and Arumugam Senthil Vel \\ Society of Integrated Coastal Management, Ministry of Environment and Forests, \\ Government of India, \#9 Institutional Area, Lodhi Road, New Delhi - 110003. \\ Email-asiramesh@yahoo.com
}

Tapas Paul and Sonia Chand Sandhu

The World Bank, Lodhi Estate, New Delhi - 110003, India

Received: March 11, 2012 Accepted: April 18, 2012 DOI: 10.5296/jpag.v2i2.1841

\begin{abstract}
The coastal areas of India are getting greater importance in recent years, owing to increasing human population, urbanization and accelerated developmental activities. These anthropogenic activities have created conflict between physical, environmental and human dimensions. Systematic knowledge and understanding of various dimensions of the coastal area shall guide for wise use of coastal resources, resolving human-induced problems, and improving governance systems. Integrated coastal management (ICM) is conceived as a holistic management tool working across sectoral, disciplinary, and institutional boundaries. Any program aimed at integrated management of the coastal zone is to meet and overcome the challenges of building up and anchoring new institutional, technical, and administrative capacity.

Capacity development on integrated management and planning are recently initiated at academic level in India. UNDP defines capacity development as "the process through which individuals, organisations and societies obtain, strengthen and maintain the capabilities to set and achieve their own development objectives over time. A capacity assessment provides a comprehensive perspective on capacities critical to the achievement of development objectives. Capacity need analysis are offering desired future capacities against current capacities and offers a systematic way of gathering critical knowledge and information on capacity asset. Capacity assessment on Integrated Coastal Zone Management (ICM) in India has been conducted by surveying published literatures through data mining from databases. In total seven thousand three hundred and fifty six indexed
\end{abstract}


research papers which were published in Indias' coastal areas between the years 1977 and 2008 were assessed for capacity need assessment purpose. The literatures were classified under sixteen subject heads which are the essential components of ICM planning process. The subject clusters were further classified into five levels viz., introductory level, process level, decision level, sustainable coastal zone management level, and innovative level. Researches where does not happened on the particular subjects were classified as "no evidence of research".

Based on the content of the literature and a skill map prepared, it is found that the literatures are mostly under introductory level and they are mostly on science subjects with few on socio-economic and management subjects. Considering the outcome of this literature survey and capacity analysis, the World Bank has accepted for financial assistance to establish National Centre for Sustainable Coastal Management at Chennai, India. The process of ICM capacity analysis in India is described in this paper.

Keywords: Integrated Coastal Zone Management, capacity analysis, data mining, literature survey, levels of subject

\section{Integrated Coastal Management}

Coastal areas are assuming greater importance in recent years, owing to increasing human population, urbanization and accelerated developmental activities. These anthropogenic activities engender colossal pressure on fragile coastal environment by its complexity due to multidimensional interactions including physical, chemical, biological, ecological, socio-economical and administrative aspects (Yeqiao Wang etal., 2005). In India, as in many other developing countries, the pressure for economic development is unrelenting in the face of widespread poverty and in practice often overrides social and environmental concerns. This is inevitably unsustainable because the environment is unable to maintain the flow of goods (e.g., resources for exploitation) and services (e.g., natural defense systems) (Le Tissier etal., 2004). Generally, approaches of coastal issues are sectoral basis and solutions formed in an adhoc fashion and inventories are not long lasting. Integration of knowledge, skills and information etc., are distributed at different levels of within the administration and different stakeholders are not happening. Setting clear goals for planning and decision making structures and processes that will integrate across these various institutions and cultures is a daunting challenge, particularly in countries where governmental institutions are weak and unstable (Stephen B. Olsen., 2002). Integrated Coastal Management (ICM) is conceived as a holistic management tool working across sectoral, disciplinary, and institutional boundaries (Burbridge, 1997; Olsen, 2000; Devaraj Asir Ramesh \& Arumugam Senthil Vel., 2011). Further, ICM is the central organizing concept in sustainable coastal development (Alf Hakon Hoel., 2003). Progress since Rio in making the transition between a concept and an operational reality is remarkable. In 1992, ICM was a fledgling discipline that was in an initial phase of discovery. Following UNCED, the concept of ICM was further defined in international events such as the 1993 World Coast Conference in Noordwijk, Netherlands, and Johannesburg summit 2002. International conferences on ICM, such as the "coastal zone Canada 2000 conference", are confirming that 
ICM has developed a general consensus on the approaches, key principles, and techniques for organizing and implementing the practice of ICM (Sorenson, 2000). Method and flow of knowledge in ICM plan process has been given in figure-1. Today, ICM has been accepted as an organizing framework for advancing societies toward long-term goals of sustainable coastal development.

\section{Capacity and gap in integrated coastal management}

The notion of capacity is defined as the ability of individuals and organizations or organizational units to perform functions effectively, efficiently, and in a sustainable manner. This implies that capacity is not a passive state but part of a continuing process, and that human resources are central to capacity development as is the overall context within which organizations undertake their functions (Jesper Duer Pedersen etal., 2005). ICM and development management research on public bureaucracies have identified key weaknesses such as chronic shortage of skills, lack of capacity for planning and collaboration, inadequate management incentives and organization structure, and inadequate institutional environment (Imperial \& Hennessey, 2000; Grindle, 1997; Lusthaus etal., 1998). In addition to administrative skills, supportive knowledge skills such as scientific data sets which can be used as a basis for informed decision making on coastal zone management are also essential (Yap, 1996). The decision makers and policy planners need data and tools to monitor and assess natural resource inventories, environmental change, and social change for sustainable development (Yeqiao Wang etal., 2005). Hence, knowledge is central to the policy and decision making process. Without knowledge there is no (perceived) problem, no public awareness, and consequently no policy process. The Co-Chair's Report from the Global Conference on Oceans and Coasts at Rio +10 reports that "the capacity of local and national governments to apply effective institutional and legal frameworks for integrated coastal and ocean management must be strengthened" (Bernal \& Cicin-Sain, 2002). In short, capacity is the power of something (a system, an organization, or a person) to perform or to produce (UNDP, 1998).

\section{Capacity assessment}

Primary factor limiting the progress in coastal management is not the availability of funding or knowledge of the social and ecosystem process at work, but the capacity of the institutions most directly involved to sustain integrated and adaptive forms of management (Stephen B. Olsen., 2002). A capacity assessment provides a comprehensive perspective on capacities critical to the achievement of a country's development objectives. It is an analysis of desired future capacities against current capacities and offers a systematic way of gathering critical knowledge and information on capacity assets and needs. UNDP has identified four core issues in capacity development they are 1) institutional arrangements 2) leadership 3) knowledge and 4) accountability (Jennifer Colville, 2008). Conducted during the initial stages of development planning, a capacity assessment serves as input to defining capacity development responses that address those areas where national and / or local capacities could be strengthened or that optimize existing capacities that are strong and well placed. It can also 
set the baseline for ongoing monitoring and evaluation of progress against relevant indicators and can help create a solid foundation for long-term planning and sustainable results (Jennifer Colville, 2008). Recognition of capacity limitations and needs is also part of the strategic and adaptive process of ICM.

\section{Literature is the source of measuring knowledge and capacity assessment}

Systematic knowledge and understanding plays a major role in guiding the wise use of coastal resources, resolving human-induced problems, and improving governance systems. Together with the parallel development of analysis tools and descriptive and forecasting models, knowledge of the environmental processes must constitute the scientific and technological basis for every decision procedure. This requirement becomes more evident as the complexity of relationships among the environment, resources, economic and social well-being of human populations are fully recognized and as changes and long-term threats are discovered (Jesper Duer Pedersen etal., 2005). Much of the required information is often in the possession of individuals in various agencies, administrations, research institutes, and universities. Further, data are often collected on the basis of very specific (and often narrow) objectives and in a wide variety of formats, including: written records, digital and hardcopy maps, satellite imagery, aerial photography, real-time data from buoys, and a range of electronic media. As a result, efforts were focused on rationalizing the various phases of information gathering, information development, and information use (Michele Capobianco, Pierluigi Caputi, Paolo De Girolamo Diego Cuzzi., 2003).

\section{Literature is the source of knowledge assessment of institution and environment.}

Thematic study on information took place between January 1998 and January 1999 as part of the European Demonstration Programme (EDP) on Integrated Coastal Zone Management (ICM). Its' main aim was to establish "the role of information in delivering ICM in Europe" based on the experiences of the 35 projects that made by EDP. It also analyzed the way in which information is provided by research institutions, local and national organizations, and the European Environment Agency. Outcome of the report has provided a broad capacity assessment on ICM which indicated the need and provisions of information at all spatial scales from international to national, regional and local levels (J. P. Doody., 2003). Andra' S Schubert \& Istva' N La' Ng., (2005) stated that a statistical overview on literature shall provide information about the trends and patterns revealed by the bibliometric/scientometric analysis of the subject.

\section{Methods - ICM knowledge capacity assessment for India}

Data mining is one step at the core of the knowledge discovery process, dealing with the extraction of patterns and relationships from large amounts of data (Michael Goebel \& Le Gruenwald., 1999). Knowledge discovery in databases is a rapidly growing field, whose development is driven by strong research interests as well as urgent practical, social, and economical needs. Knowledge discovery can be broadly defined as the automated discovery of novel and useful information from commercial databases. To assess the 
knowledge capacity on ICM, Aquatic Sciences and Fisheries Abstracts (ASFA) was used for data collection and data mining. Since all the coastal and marine related publications have been catalogued in ASFA, it is a suitable database for this ICM data analysis purpose.

ASFA was originally established in 1970 by the Food and Agriculture Organization of the United Nations (FAO). Overall objective of ASFA cooperation is to develop and maintain a service for the collection, collation and dissemination of information on the science, technology and management of marine, brackish water and fresh water environments, organisms and resources, including economic, sociological and legal aspects, in a form easily accessible to the user community, bearing in mind the special interests of developing countries and based on the pooling of literature monitoring and indexing activities by the individual partners, consistent with internationally accepted standards and practices. Aquatic Sciences and Fisheries Abstracts offers more than 800,000 citations and abstracts from the worlds published research in aquatic sciences. Input to ASFA is provided by a growing international network of information centers monitoring over 5,000 serial publications, books, reports, conference proceedings, translations and limited distribution literature (ASFA agreement. 2008). Other than databases, proceedings and newsletters published in coastal related educational institutions were also anlysed for ICM capacity assessment.

In total 7356 publications were evaluated for ICM capacity assessment purpose, of this 4500 are indexed research papers which were published around the Indias' coastal and marine areas between the years of 1977 and 2008. The literatures were classified into 16 subjects viz., physical oceanography, coastal geology/geomorphology, coastal engineering, chemical oceanography, biological oceanography, fishery, coastal ecology/environment, coastal society, uses and issues, politics, economics, legal, governance, policies/strategies, ICM, and sustainable coastal management. These 16 major subjects are basics for developing ICM framework, planning, implementation and sustainable management of the coast.

Sustainable development is the goal of ICM planning and ICM is a tool to achieve sustainable development goals. Sustainable coastal zone management requires different kinds of skills and capacity to know about the resources, functions, uses, issues and management options of the coastal areas. The inverted pyramid (figure - 1) explains the flow through of knowledge which are essentially required for sustainable coastal management and ICM plan preparation. Figure -2 has given the skill and capacity of various coastal management subjects and its level in India based on publications.

The level of content of the literature were classified into five different levels viz., [1] introductory level [2] process level [3] decision level [4] sustainable management level [5] innovative level. In the introductory level, literatures shall describe about the resources (such as list of fish species in particular area); in the process level literatures, contents are covering information about measures of the resources uses, issues and management options (such as quantity of fish species available in particular area and mechanism of efficient harvesting techniques); in decision level, literatures shall provide information to direct a 
policy decision (such as harvestable limit of the particular species in relation to fecundity and local / regional market demand); in sustainable coastal management level literatures shall provide information covering futuristic information (such as forecast, trends and impacts on other fish species considering coastal and marine system as a whole); The innovative level literatures are expected to provide information on new scientific / social / management contributions to coastal management.

\section{Capacity assessment results}

The coastal and marine area researching institutions are sharing $2.33 \%$ of the Indias' educational/research institutions. The coastal and marine related 7356 publications were contributed by 704 institutions which shall be considered that they are involved in coastal and marine related research. Out of the 7356 research papers, state level institutions have published more number of publications than the national (federal) institutions. The publications shares are $38 \%$ by national, $57 \%$ by state level and $5 \%$ by international institutions. Publications are mostly covering the biology related subjects (257) followed by fisheries (207), geology (150), ecology (145), physical oceanography (117), engineering (77), chemical oceanography (62) and uses and issues (47). Under socioeconomic aspects which cover sociology, economics, and political science related subjects only 47 institutions have published literatures. Very few institutions (26) have been involved on legal governance, policy, ICM and sustainable development subjects.

Average coast length of Indias' coastal states / union territories are $578.15 \mathrm{~km}$ and average research publications in the coastal states / Union Territory (UT) stretches are 566 only. Out of the total 7356 research papers, Tamil Nadu states' coastal stretch has been investigated frequently (1453 research papers) followed by Kerala state (1351), and Goa state (1256). Fewer investigations (51 publications) have been made for Pondicherry UT coast. The Daman and Diu UT coastal region which has a coastal length of $21 \mathrm{~km}$ does not have any research paper published so far. The correlation between coastal length $(\mathrm{km})$ and total published publications in the coastal states' stretch is positively correlated (CORREL= 0.0567). Coastal length and total number of institutions involved in coastal area research are positively correlated $(\mathrm{CORREL}=0.5620)$. State of Tamil Nadu has more (171) number of institutions followed by Kerala (163), West Bengal (141), Maharashtra (125), Orissa (119) and Gujarat (102). Total number of publications by states and per capita net state domestic product at factor cost are positively correlated $(\mathrm{CORREL}=0.61242)$

More number of state organizations / institutions have been engaged in their own states' coastal stretch rather than the number of National institutes / other states' institutes / organizations, except Orissa state. In the Union Territories (UTs') of India, where the administration are directly by Union Government have comparatively more Nationalized / Central Government participation and other State government organization engagement are high. Number of institutions involved in coastal research in the state and coastal literate population are negatively correlated $(\mathrm{CORREL}=-0.2552)$. Maharashtra state institutes / organizations have published $83.5 \%$ of coastal literatures for their own states coastal stretch, 
followed by Tamil Nadu (77\%), and West Bengal (74\%). International organization participation on publication of coastal research are high (9) in Kerala coastal stretch followed by West Bengal (8) and Andhra Pradesh (5).

Based on the literature evaluation, it is evident that $9.5 \%, 36.5 \%$ and $54 \%$ of the research publications are in decision taking level, process level and introductory level respectively. Some of the literatures have mentioned integrated coastal management and sustainable coastal management as a solution for many problems but, they have not given any directions or methods to achieve it.

\section{Discussion on ICM capacity in India}

Capacity on ICM in India is gradually increasing along with various legal and political changes. Constrains in developing the integrated coastal management in India is mainly due to poor organizational arrangement, less resources and inappropriate functioning of institutions towards sustainable management. In general, developing countries are often hampered in their attempts to tackle the environment issue owing to constraints in technical, organizational, and institutional capacities, and at a more fundamental level, paucity in financial and human resources (Ambuj D Sagar., 2000).

Quality and quantities of publications in relation to ICM subject and in various states of India are mainly due to number of institutions involved in coastal or marine related research and also by the traditional history of the institutions. Duration or history of organization/research institution functioning in the subject located in various states is an essential criterion for number of publications in the subject by the states. It is implicit that traditional narration has lots of transmission of knowledge, instruments, library, and available documents which shall help the researchers to encourage and support more number of publications. More than above, the organization who has long history in the particular subject has approved defined scope, objectives, goals, and funding provisions which have greater strength for continuing similar researches. Traditional institutes locating states have comparatively large number of literature outputs however; it is not necessarily they work on other related subjects. Institutional analysis is a relatively new area of inquiry, and understanding of the interaction of institutional variables and their influence upon management performance is poor (Nigel Watson, etal., 1996). More than above institutions emerged for environment management subjects especially coastal or marine areas hence, literature output and diversity are slowly improving. Zinn \& Blodgett (1989), stated that, many organizations with responsibilities for water and environmental resources are of more recent origin and ICM is a new subject even to the developed world.

In India, tertiary educational institutions and research organizations are contributing to the number of literatures. However, number of research and tertiary educational institutions and investment are very meager. All over the world, many national governments and international donors have assigned higher education a relatively low priority. Further, economic analysis has contributed to the view that public investment in universities and colleges brings meager returns compared to investment in primary and secondary schools 
(Peril \& Promise., 2000). The Indian higher education system consists of 20,677 colleges, 431 universities, 9000 nationally important institutions / organizations. India's current Gross Enrolment Ratio (GER) in higher education is $11 \%$ which is very low compared to the world average of $23.2 \%, 36.5 \%$ for countries in transition, $54.6 \%$ for developed countries and $22 \%$ for Asian countries. The number of Ph.Ds' awarded in Science and Engineering in India in 2003- 04 was 6,316 compared to 9,000 in China and 26,891 in the USA. Less than $0.4 \%$ of Science and Engineering graduates in India obtain doctorates compared to $7 \%$ and 4\% in Europe and the USA, respectively (Pawan Agarwal, 2006). In India, number of tertiary education students 515 and 645 during 1980 and 1995 respectively out of 1,00,000 inhabitants, which is very slow growth and low rate comparing other developing or transitional nations. Indian government is spending $11.5 \%$ of public expenditure for education.

The knowledge map is the evident for researches on coastal and marine areas are about the basic sciences and very few publications are attempting to interpret socio-economics, law and governance. This is due to the institutional and organizational scope established mostly to study basic sciences. This shows the inadequacy of institutional arrangements for developing literatures for top level strategies on coastal environment management. Institutions are predetermined with specialization and reluctant to diversify their research field. New institutions are copying the existing institutions or organizations science subject has got comparatively more number of publications. According to Peril \& Promise (2000), private universities in South Asia, for example, have introduced innovations in the form of the semester system, standardized examinations, and credit systems. Universities and research institutes are playing a key role in social science research by creating knowledge bases in concerned disciplines. While there are many reasons behind the crisis in social science research in India; perhaps the single most important reason is shortage of assured government funding of social science research. With dwindling financial support from the government, it has become almost impossible to do research (especially applied empirical research) without funding from international agencies.

Knowledge dimensions are grounding regional development dynamics (Antonio Lerro \& Giovanni Shciuma., 2009). Creation of new knowledge is closely related to factors both internal and external to the firms or institutions in which it is generated. The type of industry, its size, location, and ownership type are all factors able to affect the rate of innovation of a firm from the inside. Next to internal factors, there are external factors related to the environment in which firms operate (Laura de Dominicis etal., 2010).

\section{Conclusion}

In India, skill to attain the ICM capacity is a slow and dynamic process. Primary factor limiting the capacity development of ICM is not only the availability of funding or knowledge of the social and ecosystem process, but the capacity of the existing institutions. To improve the existing capacity of ICM in India, coastal and marine research institutions/ organizations to be structured or reorganize to facilitate "vertical" connections between the 
best coastal or marine research anywhere in the world and practical experience in particular field situations. At the same time, the coastal institutions shall foster "horizontal" connections among regional coastal and marine research institutes/organizations that should help for integrating the outcomes. Scientific networking in the $21^{\text {st }}$ century is providing sufficient diversified medias for networking. Nowadays, monopoly of publishers is diminishing due to high competition of online publishers who are publishing quality and competitive publications hence, scientists, researchers and academicians to avail the opportunity to express their views without compromise their views for the editors and journals. This can help the present understandings and views of developing nations rather than standards of northern editors. Institutionalization is more than just sharing which is happening at present, it shall strengthens the process towards a common research agenda, provides more human capacity and more resources and gives synergies for institutional growth.

Global wealth is concentrated less and less in factories, land, tools, and machinery. The knowledge, skills, and resourcefulness of people are increasingly critical to the world economy. Integrations of knowledge and capacity for sustainable use will be a most complex problem of public governing process. Its goal is to change humankind's behavior and practices in resource utilization of coastal and marine environment. To accomplish this goal, it is essential that a mutualistic relationship develop between institutions across the coastal stakeholders and natural systems. This relationship, in turn, will require a combination of coastal and marine econ-ethics and coastal and marine eco-ethics.

\section{Acknowledgement}

The authors wish to thank Ministry of Environment and Forests, and other Ministries and Departments of Government of India for accessing their data that are relevant to capacity assessment. Further, they wish to thank the World Bank officials for their support in capacity building activities in India.

\section{References}

Yeqiao Wang, James Tobey, Gregory Bonynge, Jarunee Nugranad, Vedast Makota, Amani Ngusaru, and Michael Traber, 2005. Involving Geospatial Information in the Analysis of Land-Cover Change Along the Tanzania Coast. Coastal Management, 33:87-99.

Le Tissier, M. D. A., J. M. Hills, J. A. McGregor and M. Ireland. 2004. A Training Framework for Understanding Conflict in the Coastal Zone. Coastal Management, $32: 77-88$

Stephen Olsen, 2000. Educating for the governance of coastal ecosystems: The dimensions of the challenge. Ocean and Coastal Management 43:331-341.

Stephen B. Olsen., 2002. Assessing Progress Toward the Goals of Coastal Management. Coastal Management, 30:325-345 


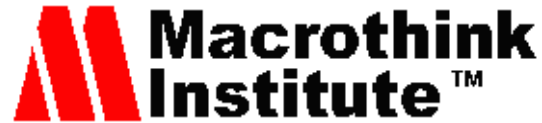

Journal of Public Administration and Governance ISSN 2161-7104 2012, Vol. 2, No. 2

Devaraj Asir Ramesh and Arumugam Senthil Vel., 2011. Methodology of integrated coastal management - case study of Andaman Islands. Journal of Environment Protection. Accepted.

Alf Håkon Hoel., 2003. Marine Biodiversity and Institutional Interplay. Coastal Management, 30:25-36.

Sorenson, J. 2000. Baseline 2000. Background paper for Coastal Zone Canada 2000: Coastal Stewardship-Lessons learned and the paths ahead. September 17-22. New Brunswick, Canada, http://www. sybertooth.ca/czczcc2000/.

Jesper Duer Pedersen, Søren Beck, Henrik Brade Johansen, and Hanne Birgitte Jensen., 2005. Capacity Development in Integrated Coastal Zone Management: Some Lessons Learned from Malaysia. Coastal Management, 33:353-372.

Imperial M., and T. Hennessey. 2000. Environmental governance in watersheds: The importance of collaboration to institutional performance. Research Paper 18, Learning from Innovations in Environmental Protections. Washington, DC: National Academy of Public Administration.

Grindle, M., Ed. 1997. Getting good government: Capacity building in the public sectors of developing countries. Cambridge, MA: Harvard Institute for International Development, Harvard University Press.

Lusthaus, C., M. Adrien, G. Andreson, and F. Carden. 1998. Enhancing organizational performance: A toolbox for self-assessment. Ottawa, Canada: International Development Research Center.

Yap, H. T. 1996. Attempts at integrated coastal management in a developing country. Marine Pollution Bulletin 32:588-591

Bernal, P., and B. Cicin-Sain. 2002. Ensuring the sustainable development of oceans and coasts: A call to action. Co-Chairs' Summary, The Global Conference on Oceans and Coasts at Rio+10, held at UNESCO, Paris, December 3-7, 2001. http://www.udel.edu/CMS/csmp /rio+10/pdf/CochairsReport.pdf .

United Nations Development Programme (UNDP). 1998. Capacity assessment and development: In a Systems and Strategic Management Context, Technical Advisory Paper, UNDP Bureau for Development Policy, 110 p.

Jennifer Colville, 2008. UNDP Practice Note: Capacity Assessment, New York, USA, pp. $1-32$

Michele Capobianco, Pierluigi Caputi, Paolo De Girolamo Diego Cuzzi., 2003. Integration of Sectoral Management Activities in the Coastal Zone of the Regione Abruzzo, Italy: The Case of RICAMA. Coastal Management, 31:175-185 
ASFA Agreement, 2008. ASFA partnership agreements.

ftp://ftp.fao.org/docrep/fao/006/ad644e/ad644e00.pdf . Pages 1-16

Ambuj D Sagar., 2000. Capacity development for the environment: A View for the South, A View for the North. Annu. Rev. Energy Environ. Vol. 25:377-439.

Nigel Watson, Bruce Mitchell and George Mulamoottil., 1996. Integrated Resource Management: Institutional Arrangements Regarding Nitrate Pollution in England. Journal of Environmental Planning and Management, 39(1), 45-64, 1996

Mitchell, B. (Ed) (1990). Integrated Water Management: International Experiences and Perspectives. London/ New York, Belhaven.

Peril and Promise. 2000. Higher education in developing countries. Published for the task force on higher education and society by the World Bank. P-1-138. ISBN 0-8213-4630 - X.

Pawan Agarwal, June 2006, Higher Education in India: Need for Change, ICRIER Working Paper No. 180, ICRIER

Antonio Lerro and Giovanni Shciuma., 2009. Knowledge based dynamics of regional development : the case of Basilicata region. Journal of knowledge management, Vol. 13, No. 5, p. 287-300.

Laura de Dominicis, Raymond J.G.M. Florax, Henri L.F. de Groot., 2010. Tinbergen Institute Discussion Paper, Erasmus University Rotterdam, the University of Amsterdam and VU University Amsterdam. TI 2011-009/3. Pages 1- 25. 


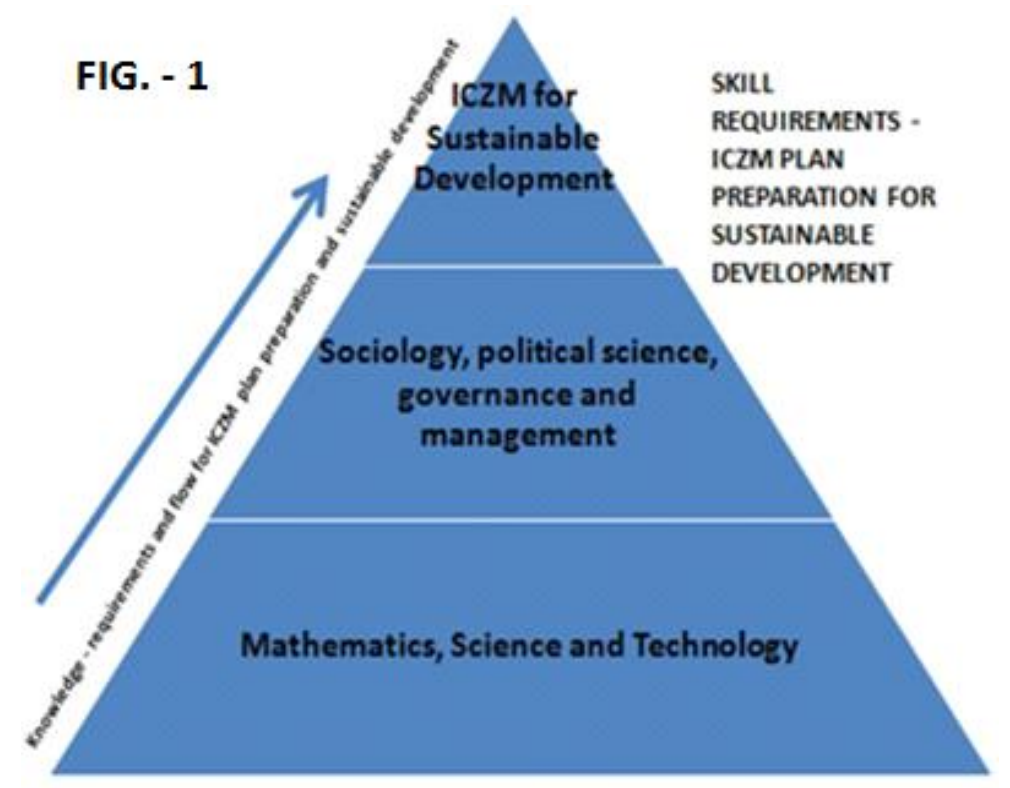

